\title{
Analisis Psikometri Intelligenz Structur Test (IST) pada Mahasiswa
}

\author{
Ivan Muhammad Agung $^{1}$, Ahyani Radhiani Fitri ${ }^{2}$ \\ ${ }^{1,2}$ Fakultas Psikologi, Universitas Islam Negeri Sultan Syarif Kasim Riau
}

\begin{abstract}
Abstrak
Intelligenz structur Test (IST) merupakan salah satu tes inteligensi yang paling banyak digunakan di Indonesia.Penelitian ini bertujuan untuk menganalisis psikometrik IST yang meliputi reliabilitas dan validitas alat ukur. Subjek penelitian merupakan mahasiswa tahun pertama dengan jumlah 689 (wanita 531 dan pria 158) mahasiswa UIN Suska Riau. Hasil penelitian menunjukkkan bahwa reliabitas secara keseluruhan baik, jika dianalis per subtes menunjukkan 3 subtes memiliki reliabilitas buruk, 3 subtes cukup dan 3 subtes memiliki reliabilitas baik. Semantara Validitas konstrak menunjukkan bahwa tes ini memiliki validitas kosntrak yang baik secara psikometris, artinya setiap komponen mencerminkan kevalidan tes IST. Hasil dan implikasi penelitian dibahas dalam konteks pengukuran psikologi.
\end{abstract}

Kata kunci: tes, inteligensi, reliabilitas, validitas

\begin{abstract}
The Intelligenz structur Test (IST) is one of the most widely used intelligence tests in Indonesia. This research aims to analyze the IST's psychometric analysis which includes reliability and validity. The research subjects were first-year students with a total of 689 (531 women and 158 men) UIN Suska Riau students. The results showed that overall reliability was good, if analyzed per sub-test showed 3 sub-tests had poor reliability, 3 sub-tests were sufficient and 3 sub-tests had good reliability. While the validity of the constructs indicates that this test has a good psychometrically validity, meaning that each component reflects the validity of the IST test. The results and implications of the study are discussed in the context of psychological measurement.
\end{abstract}

Keywords: Test, intelligence, reliability, validity

\section{Pendahuluan}

Psikologi merupakan ilmu yang berusaha menjelaskan, menggambarkan dan memprediksi perilaku, kemampuan dan kondisi psikologis seseorang. Salah satu alat yang digunakan adalah melalui tes psikologi. Tes adalah alat pengukuran yang digunakan untuk mengukur perilaku atau membantu memahami dan memprediksi perilaku. Tes psikologi terdiri dari seperangkat item yang dirancang untuk mengukur karakteristik manusia yang berhubungan dengan perilaku (Kaplan \& Saccuzo, 2012).

Perkembangan tes psikologi dalam memahami perilaku manusia sudah sejak lama terjadi khususnya untuk seleksi pegawai atau tentara. Pada awalnya penggunaan tes psikologi dilakukan di Cina untuk menseleksi wajib militer sekita 4000 tahun tahun lalu. Kemudian Inggris dan Negara Eropa mengadopsi model tes yang digunakan di 
Ivan, Ahyani :

Analisis Psikometri Intelligenz Structur Test (IST) pada Mahasiswa

Cina. Selanjutnya perkembangan pengukuran dalam psikologi dibagi dua, pertama fokus pada perbedaan individu yang dimotori oleh Darwin, Galton dan Cattel. Kedua fokus penelitian eksperimen dan metode ilmiah dalam melakukan pengukuran yang dimotori oleh psikofisika Jerman, Herbat, Weber, Fechner dan Wundt (Kaplan \& Saccuzo, 2012).

Teroboson baru dalam tes psikologi terjadi pada abad 20 yang dimotori Alfred Binet dan T. Simon, yang menghasilkan tes inteligensi yang dinamakan skala BinetSimon pada tahun 1905. Perkembangan zaman dan tuntutan pada pengukuran yang lebih akurat mulai bnayak dilakukan pada tahun 1930. Banyak ahli psikologi mengkritik atas tes Binet yang masih banyak kelemahan terutama terlalu focus pada bahasa dan kemampauan verbal sehingga tidak cocok untuk beberapa orang (Kaplan \& Saccuzo, 2012).Hal tersebut mendorong banyak ahli psikologi yang membuat tes-tes inteligensi seperti, Stanford-Binet intelligence, Wechsler intelligence scale dan Intelegenz structure test (IST).

Salah satu tes yang banyak digunakan dalam pengukuran inteligensi adalah Intelegenz structure test (IST). IST merupakan salah satu tes inteligensi yang dikembangkan oleh Rudolf Amthaeur di Jerman pada tahun 1953. Tes ini bertujuan untuk mengukur inteligensi berdasarkan pada 9 komponen, yaitu Intelligenz Struktur Test (IST) memuat 9 subtes antara lain Satzerganzung (SE) yaitu melengkapi kalimat, Wortauswahl (WA) yaitu melengkapi kata kata, Analogien (AN) yaitu persamaan kata, Gemeinsamkeiten (GE) yaitu sifat yang dimiliki bersama, Rechhenaufgaben (RA) yaitu kemampuan berhitung, Zahlenreihen (SR) yaitu deret angka, Figurenauswahl (FA) yaitu memilih bentuk,Wurfelaufgaben (WU) yaitu latihan balok, dan Merkaufgaben (ME) yaitu latihan simbol (Kumolohadi \& Suseno, 2012)

Penggunaan tes IST telah banyak dilakukan termasuk dalam bidang penelitian. Penelitian yang menggunakan pengukuran inteligensi dengan menggunakan tes IST sudah banyak dilakukan di Indonesia, misalkan, peneltian Kumolohadi dan Suseno, (2012) tentang pengukuran tes inteligensi yang menggunakan tes IST dan SPM, Setyabudi (2011) tentang hubungan adversity dan inteligensi dengan kreativitas. Sementara penelitian khusus tentang psikometris pada tes IST sudah beberapa dilakukan di Indonesia, seperti, penelitian Rahmawati (2014) tentang evaluasi tes IST yang berkaitan dengan kesukaran aitem, daya diskriminasi aitem dan peluang tebakan semu dengan pendekatan item respon theory. Hasil analisis menunjukkan bahwa $53.125 \%$ dari aitem-aitem IST yang dianalisis memiliki karakteristik psikometri yang kurang baik menurut batasan psikometri.

Penelitian sebelumnya dilakukan oleh Winarti (1998) tentang validasi, dan standariasasi tes IST. Penelitian dilakukan pada 562 siswa SMA. Hasil yang diperoleh menunjukkan: (1) validitas tes IST secara internal maupun eksternal ternyata cukup baik; ( 2 ) ada dua faktor yang dapat diungkap oleh tes IST, yaitu faktor verbal dan faktor non-verbal; dan (3) dapat tersusun norma standar tes IST untuk masing-masing subtes maupun tes secara keseluruhan. Penelitian Bonang (2008) meneliti tentang 
validiats dan reliabilitas tes IST khususnya pada subtes ME yang mengukur kemampuan long term memory. Penelitian dilakukan pada dua kelompok usia berbeda, yaitu kelompok adolescent (13-20) dan kelompok dewasa madya (40-60). Hasilnya menunjukkan bahwa usia memiliki hubungan dengan fungsi long-term memory manusia. Hal itu juga membuktikan subtes ME valid dalam mengukur konstruk memori. Pengujian reliabilitas menghasilkan koefisien reliabilitas yang memenuhi syarat reliabilitas alat tes, sehingga dapat dikatakan bahwa subtes ME cukup reliable dalam mengukur long-term memory seseorang.

Penelitian oleh Siregar (2011) tentang karakteristik psikometri subtes AN pada Tes IST menunjukkan perlu adanya peninjauan ulang terhadap subtes AN di IST yang digunakan dalam proses seleksi P3M atau Pusat Penelitian dan Pengabdian pada Masyarakat di Fakultas Psikologi Universitas Sumatera Utara. Sari (2015) menemukan bahwa $45 \%$ aitem pada subtes RA versi revisi memiliki indeks kesukaran yang dianggap baik, 55\% aitem masih memerlukan peninjauan ulang, serta mampu memberikan total informasi sebesar 76,46 \% mengenai kemampuan berpikir praktis tentang bilangan individu berusia 13 sampi 23 tahun pada penelitiannya tentang karakteristik psikometri subtes RA versi revisi pada IST. Selain itu, Elvira (2011) yang meneliti tentang IST khususnya pada subtes SE menyarankan perlunya peninjauan ulang terhadap aitem subtes SE sebelum digunakan dalam proses seleksi yang dilakukan oleh P3M Fakultas Psikologi USU. Sirait (2011) juga menyarankan adanya revisi aitem pada subtes WA agar hasil subtes ini dapat dipergunakan secara memuaskan sesuai dengan tujuannya. Hal ini merupakan temuan penelitian Sirait yang menggunakan teori skor murni klasik pada analisis 20 aitem di WA. Berbeda dengan temuan pada analisis subtes ZR yang dilakukan oleh Princen (2011) yang menemukan bahwa kualitas IST subtes ZR sudah cukup baik.

Tes psikologi sangat rentan dengan dipengaruhi oleh faktor eksternal seperti factor budaya. Tes inteligensi seringkali menimbulkan bias budaya, artinya tes inteligensi dirancang untuk satu budaya sehingga seringkali tidak cocok dengan budaya lain walaupun sudah diterjemahkan secara tepat secara bahasa (Matsumoto, 1994). Tes IST dikembangkan di Jerman dan berkembang sampai ke Indonesia. Tes IST masuk ke Indonesia pada tahun 1970. Adapatsi tes IST pertama kali dilakukan oleh UNPAD yang digunakan untuk diagnosis dan prognosis.

Tes IST di Indonesia banyak digunakan untuk seleksi dan penempatan pegawai, seleksi masuk siswa dan mahasiswa dan serta dapat melihat minat dan bakat seseorang. Uji psikometris telah banyak dilakukan oleh peneliti dalam konteks Indonesia. Namun hasilnya belum tersosialisasi dengan biak sehingga menimbulkan perubahan atau modifikasi tes IST.Selain itu,permasalahan dalam penggunaan tes IST adalah penggunaan norma IST dalam konteks Indonesia. Selama ini, masih banyak penggunaan interpretasi IQ menggunakan norma asli tes yang berasal dari Negara Jerman. Penggunaan norma IQ versi Indonesia sudah mulai digunakan walaupun bersifat lokal, artinya belum ada kesepakatan atau acuan norma secara bersama dalam 
Ivan, Ahyani :

Analisis Psikometri Intelligenz Structur Test (IST) pada Mahasiswa

menginterpretasikan skor inteligensi IST. Hal tersebut tentunya menimbulkan permasalahan khususnya dalam menginterpretasikan hasil skor IQ.

Berdasarkan permasalahan yang telah diurakan, maka perlunya mengkaji atau meneliti lebih lanjut fungsi tes IST secara psikometris khusus pada mahasiswa di UIN Suska Riau karena kajian tentang ini belum pernah dilakukan sebelumnya. Hal ini menjadi penting karena hasil dari penelitian ini dapat melihat apakah tes ini dapat berfungsi secara baik untuk mengukur kemampuan inteligensi mahasiswa. Selain itu, penelitian ini diharapkan menghasilkan suatu norma yang dapat digunakan menginterpretasi hasil tes sesuai dengan norma yang berasal dari Indonesia khususnya dengan subjek pengguna tes dari Riau.

Tujuan penelitian ini adalah untuk melihat fungsi dari tes IST dalam mengukur inteligensi yang dilihat dari aspek psikometris yang meliputi uji reliabilitas, dan validitas konstrak.

\section{Metode}

Pendekatan yang digunakan dalam penelitian ini adalah pendekatan kuantitatif, yaitu suatu penelitian yang lebih menekankan analisis datanya pada penggunaan angka yang diolah secara statistic (Prasetyo, \& Jannah, (2005). Desain Penelitian kuantitatif yang digunakan adalah penelitian deskriptif, yaitu penelitian yang bertujuan untuk menggambarkan karakteristik data penelitian (mean, SD, dll) yang bertujuan agar data dapat mudah dipahami dan simpulkan.

Pemilihan sampel dalam penelitian ini adalah menggunakan teknik sampling purposif, yaitu penentuan subjek penelitian berdasarkan tujuan penelitian, yaitu ingin menguji analisis psikometri dan membuat standarisasi norma tes IST pada mahasiswa tahun pertama. Lokasi penelitian adalah di UIN Suska Riau. Jumlah subjek penelitiannya adalah sebesar 689 mahasiswa (wanita 531 dan pria 158) dengan rentang umur 17-22 (mean=18,5).

Alat pengumpul data yang dilakukan menggunakan tes inteligensi yaitu IST. Tes IST merupakan salah satu tes Inteligensi yang banyak digunakan di Indonesia. Tes IST ini terdiri dari 9 subtes, masing masing-masing subtes mengukur bagian-bahian terstentu, komponen, yaitu Intelligenz Struktur Test (IST) memuat 9 subtes antara lain :Satzerganzung (SE) yaitu melengkapi kalimat, Wortauswahl (WA) yaitu melengkapi kata kata, Analogien (AN) yaitu persamaan kata, Gemeinsamkeiten (GE) yaitu sifat yang dimiliki bersama, Rechhenaufgaben (RA) yaitu kemampuan berhitung, Zahlenreihen (SR) yaitu deret angka, Figurenauswahl (FA) yaitu memilih bentuk, Wurfelaufgaben (WU) yaitu latihan balok, dan Merkaufgaben (ME) yaitu latihan symbol (Kumolohadi \& Suseno, 2012) 
Tabel 1

Statistk deskriptif dan reliabilitas subtes IST

\begin{tabular}{|c|c|c|c|c|c|c|c|c|c|}
\hline No & Subtes & Nama & Min & Max & Mean & SD & Variance & Alpha & ket \\
\hline 1 & $\mathrm{SE}$ & $\begin{array}{l}\text { Melengkapi } \\
\text { kalimat }\end{array}$ & 0 & 19 & 7.53 & 2.420 & 5.857 & 0.46 & $\begin{array}{l}\text { Sangat } \\
\text { buruk }\end{array}$ \\
\hline 2 & WA & $\begin{array}{l}\text { Persamaan } \\
\text { kata }\end{array}$ & 3 & 19 & 10.84 & 2.670 & 7.131 & 0.49 & $\begin{array}{l}\text { Sangat } \\
\text { buruk }\end{array}$ \\
\hline 3 & $\mathrm{AN}$ & $\begin{array}{l}\text { Analogi } \\
\text { verbal }\end{array}$ & 0 & 18 & 6.92 & 2.722 & 7.409 & 0.56 & Buruk \\
\hline 4 & GE & $\begin{array}{c}\text { Sifat yang } \\
\text { sama }\end{array}$ & 0 & 24 & 11.62 & 4.457 & 19.864 & 0.64 & Cukup \\
\hline 5 & RA & Berhitung & 0 & 17 & 3.97 & 2.269 & 5.149 & 0.65 & Cukup \\
\hline 6 & ZR & $\begin{array}{l}\text { Deret } \\
\text { angka }\end{array}$ & 0 & 19 & 6.56 & 3.517 & 12.366 & 0.80 & Bagus \\
\hline 7 & FA & $\begin{array}{c}\text { Memilih } \\
\text { gambar }\end{array}$ & 0 & 18 & 8.03 & 3.172 & 10.060 & 0.63 & cukup \\
\hline 8 & WU & Kubus & 0 & 20 & 7.84 & 3.406 & 11.602 & 0.78 & Bagus \\
\hline 9 & $\mathrm{ME}$ & Ingatan & 0 & 23 & 12.66 & 4.498 & 20.234 & 0.82 & $\begin{array}{l}\text { Sangat } \\
\text { Bagus }\end{array}$ \\
\hline
\end{tabular}

Analisis data digunakan dalam penelitian adalah anaslsis data deskriptif, yaitu analisis data yang bertujuan menggambar data penelitian agar mudah dipahami. Analisis data deskriptif (mean, SD) merupakan teknik yang digunakan untuk pembuatan norma tes IST. Analisis data dibantu dengan program SPSS. Selain itu, untuk analisis psikometris digunakan AMOS yang digunakan untuk melihat validitas konstrak subtes IST.

\section{Hasil}

Tes IST merupakan tes yang mengukur kecerdasan umum. Namun demikian tes ini dapat mengukur kecerdasan spesifik, seperti kecerdasan verbal, angka, figura dan ingatan (LPSP3 UI. 2012). Subjek pada penelitian ini adalah mahasiswa UIN Suska Riau tahun pertama yang berjumlah 689. Hasil statistik deskriptif, yang meliputi nilai minimal, maksimal, rata-rata (mean), varians dan simpangan baku (SD) pada 9 subtes dapat dilihat pada Tabel 1. Sementara hasil uji reliabilitas dengan konsistensi internal (alpha) menunjukkan hasil yang beragam. Subtes ingatan (ME) merupakan subtes yang memiliki reliabilitas tertinggi yaitu 0.82 , sedangkan subtes yang memiliki reliabilitas terendah adalah melengkapi kalimat (SE). sementara jika dianalisis secara keseluruhan IST $(\mathrm{M}=75,9 \mathrm{SD}=17,75)$ memiliki reliabilitas yang baik yakni sebesar 0.89. 
Ivan, Ahyani :

Analisis Psikometri Intelligenz Structur Test (IST) pada Mahasiswa

Tabel 2

Interkorelasi antar subtes IST

\begin{tabular}{|c|c|c|c|c|c|c|c|c|c|c|}
\hline Subtes & SE & WA & $\mathbf{A N}$ & GE & RA & ZR & FA & WU & ME & $\begin{array}{l}\text { Skor } \\
\text { total }\end{array}$ \\
\hline SE & 1 & & & & & & & & & \\
\hline WA & $.343^{* *}$ & 1 & & & & & & & & \\
\hline AN & $.395^{* *}$ & $.422^{* *}$ & 1 & & & & & & & \\
\hline GE & $.298^{* *}$ & $.283^{* *}$ & $.332^{* *}$ & 1 & & & & & & \\
\hline RA & $.327^{* *}$ & $.305^{* *}$ & $.436^{* *}$ & $.314^{* *}$ & 1 & & & & & \\
\hline ZR & $.321^{* *}$ & $.407^{* *}$ & $.403^{* *}$ & $.329^{* *}$ & $.528^{* *}$ & 1 & & & & \\
\hline FA & $.267^{* *}$ & $.294^{* *}$ & $.317^{* *}$ & $.252^{* *}$ & $.307^{* *}$ & $.298^{* *}$ & 1 & & & \\
\hline WU & $.131^{* *}$ & $.184^{* *}$ & $.204^{* *}$ & $.159^{* *}$ & $.244^{* *}$ & $.291^{* *}$ & $.319^{* *}$ & 1 & & \\
\hline $\mathrm{ME}$ & $.201^{* *}$ & $.307^{* *}$ & $.238^{* *}$ & $.282^{* *}$ & $.288^{* *}$ & $.310^{* *}$ & $.210^{* *}$ & $.147^{* *}$ & 1 & \\
\hline $\begin{array}{l}\text { Skor } \\
\text { Total }\end{array}$ & $.557^{* *}$ & $.630^{* *}$ & $.653^{* *}$ & $.558^{* *}$ & $.653^{* *}$ & $.715^{* *}$ & $.597^{* *}$ & $.509^{* *}$ & $.608^{* *}$ & 1 \\
\hline
\end{tabular}

Tes IST merupakan pengukuran inteligensi yang bersifat umum, yang terdiri dari 9 subtes. Semua subtes salaing berkorelas satu sama lain. Hasil tersebut didukung oleh hasil penelitian ini yang menunjukkan 9 subtes saling berkorelasi signifikan. Nilai korelasi antar subtes yang paling tinggi adalah antara RA dan AN, WA dan AN. Sementara semua subtes berkorelasi signifikan dengan skor total tes, hal ini menunjukkan bahwa semua subtes merupakan bagian yang saling mendukung satu sama lain untuk mengukur inteligensi (lihat Tabel 2).

Tabel 3

Hasil ukuran kecocokan (Fit Measures) model IST

\begin{tabular}{lccc}
\hline Goodness of fit index & Cut of value & Hasil Model & Keterangan \\
\hline Chi square & Kecil/rendah & 92.148 & kecil \\
Probability & $\mathrm{p}>0,05$ & 0.000 & Kurang baik \\
RMSEA & $\leq 0,08$ & 0.059 & baik \\
GFI & $\geq 0,9$ & 0.97 & baik \\
AGFI & $\geq 0,9$ & 0.95 & baik \\
CFI & $\geq 0,9$ & 9.48 & baik \\
RMR & $\leq 0,05$ & 0.35 & Kurang baik \\
CMIN/DF & $\leq 2$ atau 3 & 3 & baik \\
\hline
\end{tabular}

Pengujian validitas menggunakan validitas konstrak dengan confrmatori factor analisis dengan AMOS 6. Pengujian model dilakukan terhadap 9 subtes IST. Hasil menunjukkan bahwa chi square menunjukkan angka besar yaitu 92.148 dengan 
signifikansi $0,000(\mathrm{p}<0,05)$. Hal ini mengindikasikan bahwa model tidak memenuhi kriteria fit. Pengujian chi square cenderung sensitive pada jumlah sampel yang besar sehingga perlu kriteria tambahan seperti CFI, GFI, AGFI, CMIN/DF, yang menunjukkan semua memenuhi kriteria yang tetapkan (lihat Tabel 3).

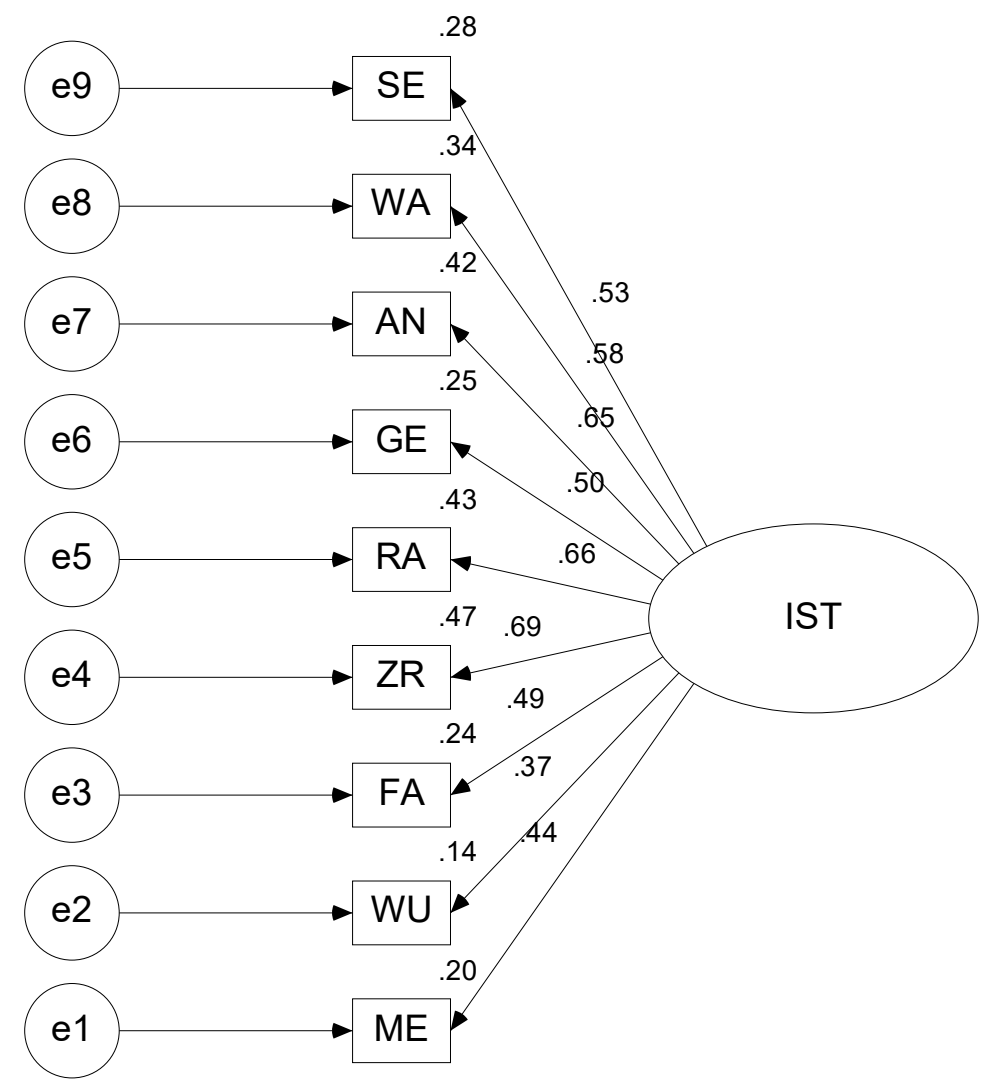

Gambar 1. Nilai standardize estimate pada model IST

Pada pengujian subtes terlihat semua memiliki faktor loading $>0,5$, kecuali subtes WU. Namun semua berkontribusi signifikan terhadap model. faktor loading yang terbesar ada pada subtes ZR, yiatu sebesar 0,69, sementara yang terendah ada subtes WU sebesar 0,37 (lihat tabel 4).

\section{Pembahasan}

Penelitian bertujuan untuk menganalisis secara psikometris Tes IST, yang meliputi uji reliabilitas per subtes dan secara keseluruhan, dan uji validitas konstrak.Hasil penelitian menunjukkan secara umum reliabilitas subtes ini baik, namun jika dianaslisis per subtes menunjukkan hasil yang beragam. Ada 3 subtes yang memiliki reliabilitas buruk, 3 kategori cukup dan 3 kategori baik. Jika dilihat pada subtes yang memiliki reliabitas yang kurang baik, menunjukkan daya diskriminasi aitem 
Ivan, Ahyani :

Analisis Psikometri Intelligenz Structur Test (IST) pada Mahasiswa

dibawah dari 0,3 artinya aitem yang ada tidak berfungsi secara baik sehingga tidak mampu membedakan kemampuan individu. Hasil penelitian ini relatif sama dengan penelitian Rahmawati (2014) yang menyatakan bahwa $53.125 \%$ atem pada IST memiliki karakteristik psikometris yang kurang baik.

Tabel 4

Faktor loading subtes IST

\begin{tabular}{ccc}
\hline Subtes & Factor loading & ket \\
\hline sSE & .53 & Signifikan \\
WA & .58 & idem \\
AN & 65 & idem \\
GE & .50 & idem \\
RA & .66 & idem \\
ZR & .69 & idem \\
FA & .49 & idem \\
WU & .37 & idem \\
ME & .44 & idem \\
\hline
\end{tabular}

Ket $\mathrm{N}=689$

Ada beberapa faktor yang dapat menyebabkan reliabilitas menjadi rendah. Pertama, kualitas aitem berperan penting dalam meningkatkan reliabilitas. Tes IST sudah memiliki kualitas aitem yang baik secara isi, namun hasilnya menunjukkan bahwa terdapat subtes yang memiliki reliabilitas rendah. kualitas tidak cukup, ada faktor lain yaitu karakteristik subjek penelitian, yang meliputi karakteristik kepribadian dan eror dari subjek. Hal ini yang tidak bisa dikontrol oleh peneliti.Kedua, kesalahan pengukuran. Reliabilitas yang baik ditunjukkan dengan eror kecil pada setiap pengukuran (Furr, 2011). Penelitian Sasmita (2010) menunjukkan bahwa sebagian besar subtes IST memiliki kesalahan pengukuran, kesalahan aitem berkorelasi dengan kesalahan aitem lain..Ketiga, daya beda aitem. Furr (2011) konsisten aitem yang ditunjukkan dengan korelasi aitem dapat mempengaruhi reliabilitas. Hasil penelitian ini menunjukkan bahwa pada subtes yang memiliki reliabilitas rendah, korelasi antar aitemnya juga rendah.artinya setiap aitem tidak mengukur sauatu kontrak yang sama, namun juga mengukur pada aspek lain. Dampaknya aitem tidak memiliki reliabilitas yang baik secara psikometris.

Sementara uji validitas konstrak pada semua subtes menunjukkan bahwa semua subtes memiliki kontribusi signifikan terhadap pengukuran inteligensi umum. Hasil ini sudah terkonfirmasi lewat korelasi antar subtes yang memiliki hubungan signifikan (lihat tabel 2). Hasil ini agak berbeda dengan penelitian hasil penelitian Sasmita (2010) yang menunjukkan bahwa terdapat beberapa subtes yang tidak valid dalam pengukuran inteligensi umum, seperti subtes SE, WA, WU dan FA. Namun demikian secara umum subtes tersebut dapat diterima dalam pengukuran tes inteligensi umum.

Pada akhirnya, penelitian ini memiliki beberapa keterbatasan, pertama, pendekatan yang digunakan dalam pengujian masil pendekatan teori klasik. Kedua, 
pengujian validitasnya belum bervariasi sehingga akan memperoleh gambaran yang lebih komprehensif. Terakhir, karakteristik subjek masih homogen, perlu subjek yang hetorogen sehingga hasil akan lebih kuat untuk generalisasi.

\section{Kesimpulan}

Secara umum uji reliabilitas tes ISTdikatakan baik secara psikometris , tetapi jika diuji reliabilitas pada setaip subtes IST, terdapat reliabilitas bervariasi. Ada 3 subtes yang memiliki reliabitas buruk (SE, WA, AN), 3 kategori cukup (GE, RA, FA) dan 3 kategori bagus (ZE, WU, ME). Jika dilihat uji korelasi antar subtes dan antar subtes dengan skor total menunjukkan bahwa semua subtes berkorelasi signifikan dengan skor total. Hal ini menunjukkan bahwa subtes mendukung pengukuran konstrak inteligensi pada IST sementara ketika diuji vakliditas konstrak menunjukkan bahwa secara umum subtes yang ada di IST memiliki validitas konstrak yang baik secara psikometris. Namun demikian perlu perbaikan secara isi untuk menyesuaikan dengan perkembangan zaman, dan perubahasan sosial dan teknologi sehingga hasil pengukuran lebih valid dan akurat.

\section{Referensi}

Bonang, E. T. (2008). Uji Aspek-Aspek Psikometrik Subtes Merkaufgaben dari Baterai Intelligenz Struktur Test. Tesis. Fakultas psikologi Atmajaya. Dari https://lib.atmajaya.ac.id/default.aspx?tabID $=61 \&$ src $=$ k\&id=151522

Elvira, R. (2011). Karakteristik Psikometri Subtes Satzerganzung (SE) Pada Intelligenz Stuktur Tes (IST). Skripsi. Medan: Fakultas Psikologi, Universitas Sumatera Utara.

Furr, R. M. (2011). Scale construction and psychometrics for social and personality psychology. SAGE Publication: London.

Kaplan, R. M \& Saccuzo, D.P (2012). Pengukuran Psikologi:Prinsip, Pennerapan, dan isu. Edisi 7.penerjemah eko Prasetyo widodo. Jakarta:Salemba Humanika.

Kumolohadi, R., \& Suseno, M. N (2012). Intelligenz Struktur Test Dan Standard Progressive Matrices: (Dari Konsep Inteligensi Yang Berbeda Menghasilkan Tingkat Inteligensi Yang Sama) Jurnal Inovasi dan Kewirausahaan, 12 , 79-85.

LPSP3 UI. (2012) . Intelligenz Struktur Test, Manual dan Norma. Jakarta. LPSP3 Fakultas Psikologi UI.

Matsumoto, D, (1994), Pengantar Psikologi Lintas Budaya, Yogyakarta; Pustaka Pelajar.

Princen. (2011). Karakteristik Psikometri Subtes Zahlenreihen (ZR) Pada Intelligenz Stuktur Tes (IST). Skripsi. Medan: Fakultas Psikologi, Universitas Sumatera Utara. 
Ivan, Ahyani :

Analisis Psikometri Intelligenz Structur Test (IST) pada Mahasiswa

Rahmawati, E.(2014). Evaluasi Karakteristik Psikometri Intelligenz Struktur Test.Proceeding Seminar Nasional Psikometri,hal 270-282.

Rismiyati, 1997. Aspek Intelegensi dan Pengukurannya. Konsep Dasar Serta Strategi Pemahaman Psikodiagnostik. Dalam Elmira, N. Sumintardja, dan Rismiyati. Jakarta: Pelatihan Psikodiagnostik PT Charoen Pokphand Indonesia.

Sari, W. L. (2015). Karakteristik Psikometri Subtes Rechenaufgaben (RA) Versi Revisi Pada Intelligenz Stuktur Tes (IST). Skripsi. Medan: Fakultas Psikologi, Universitas Sumatera Utara.

Sasmita, N.O. (2010).Pengujian validitas Konstrak dari Psikometri Intelligenz Struktur Test (IST) yang telah direvisi BPPT. Skripsi (tidak dipublikasi). Fakultas Psikologi UIN Syarif Hidayatullah.

Setyabudi, I. (2011). Hubungan antara adversiti dan inteligensi dengan kreativitas. Jurnal Psikologi Volume 9 (1),1-8

Siratit, D. (2011). Karakteristik Psikometri Subtes Wortauswahl (WA) Pada Intelligenz Stuktur Tes (IST). Skripsi. Medan: Fakultas Psikologi, Universitas Sumatera Utara.

Siregar, F. S. (2011). Karakteristik Psikometri Subtes Analogien (AN) Pada Intelligenz Stuktur Tes (IST). Skripsi. Medan: Fakultas Psikologi, Universitas Sumatera Utara.

Tim Penulis Modul Administrasi dan Skoring Tes Psikologi. (2012). Administrasi dan Skoring Tes Psikologi. Pekanbaru: Fakultas Psikologi, UIN SUSKA Riau.

Winarti, S. (1998). Validasi, Faktorisasi Dan Standarisasi Norma Tes Intelegensi IST. Tesis. Fakultas Psikologi $\quad$ UGM. Dari Http://Etd.Repository.Ugm.Ac.Id/Index.Php?Mod=Penelitian_Detail\&Sub=Pene litiandetail\&Act=View\&Typ=Html\&Buku_Id=3140 